\title{
SARS-CoV-2 infection prevalence and characteristics in domestic contacts: Study of 39 families and 132 people in a general medicine clinic in Toledo (Spain): Implications for the general practitioners
}

Jose Luis Turabian

Health Center Santa Maria Benquerencia. Regional Health Service of Castilla la Mancha (SESCAM). Toledo, Spain.

*. Corresponding author: Turabian, J.L. Health Center Santa Maria Benquerencia. Toledo, Spain. E-mail: jturabianf@hotmail.com.

Cite this article: Turabian J.L. SARS-COV-2 infection prevalence and characteristics in domestic contacts: Study of 39 families and 132 people in a general medicine clinic in Toledo (Spain): Implications for the general practitioners. Int J Epidemiol Health Sci 2021;2(1): e02. Doi: 10.51757/IJEHS.2.2.2021.241686.

\author{
Abstract \\ Background: Most people with COVID-19 receive care at home, increasing the likelihood of exposure for household \\ members.
}

Objective: To study the prevalence and characteristics of secondary cases in families after the appearance of a primary case.

Methodology: An observational and retrospective study of families with at least one polymerase chain reaction (PCR) confirmed COVID-19 primary case was conducted from March 15 to December 25, 2020, in a general medicine office in Toledo, Spain. Socio-demographic and clinical variables were compared between primary and secondary cases in the families. The outcome of interest was secondary attack rate of SARS-CoV-2 within the family.

Results: 39 families with a primary case (average size 3.4 members) with a total of 132 cohabitants were included. There were 22 cohabitants with negative PCR $(22 / 92=24 \%), 70$ secondary cases with positive PCR (Secondary attack rate $76 \%)$, of which 25 were asymptomatic $(25 / 70=36 \%)$, and a cohabiting new-born. A high frequency of people from ethnic minorities, low household income and complex families was found, both in primary and secondary cases. The secondary cases with respect to the primary ones were more women, younger, students and with a lower sociooccupational level, with more asymptomatic cases, and milder symptomatic cases.

Conclusion: In this context the prevalence of secondary domestic contacts is very high, and it occur in young women, being asymptomatic or mild. The high secondary attack rate suggests the importance of the pre-symptomatic or early symptomatic period of COVID-19, as well as the possible failure to comply with isolation measures.

Keywords: COVID-19; SARS-CoV-2; Household contact; Family Characteristics; Secondary attack rate

\section{Introduction}

The severe acute respiratory syndrome coronavirus 2 (SARS-CoV-2), which causes coronavirus disease 2019 (COVID-19), emerged in December 2019 in Wuhan, China (1). Since then, a global pandemic has been declared with nearly 84 million cases reported as of January 2, 2021 (2). Person-to-person transmission has been established (3-6) and asymptomatic transmission of SARS-CoV-2 has been reported (7). The infectivity during the incubation period for SARS$\mathrm{CoV}-2$ is a big challenge for controlling the disease. 
Higher levels of virus can occur in presymptomatic and asymptomatic patients. Presymptomatic and asymptomatic transmission significantly reduces the effectiveness of control measures that start with the onset of symptoms, such as isolation and follow-up of contacts $(8,14)$.

Thus, numerous familial clusters of COVID-19 involving asymptomatic and paucisymptomatic transmission have been reported. Additionally, SARSCoV-2 has been detected in contaminated environments of household (15-19). Outbreaks involving transmission within large multigenerational households show the importance of implementing the appropriate public health measures now to prevent sudden increases in infections (20).

Current test and trace policies have focused primarily on preventing the spread in nursing homes, hospitals, and in the community (21). However, contact within homes is believed to be responsible for approximately $70 \%$ of SARS-CoV-2 transmission when widespread community control measures are in place (22). Household contacts that are isolated within the same home as the index case make up most of the infected person's contacts and are likely to remain exposed to the infected household member during this period of isolation (23).

Although the guidelines advise household members to distance themselves socially, contacts are likely to interact repeatedly — for example, during meals and share facilities such as bathrooms. It is known that transmission is more likely to occur indoors than outdoors (24). The cumulative risk to household contacts of an infected person is likely to be substantial during the peak of viral shedding. In a study in New York State, $38 \%$ of household contacts tested positive for SARS-Cov-2 (25), and similar rates of secondary infection have been reported in China (26).

In this context, most people with COVID-19 receive care at home, which increases the probability of exposure of household members, and the transmission of COVID-19 within families and close contacts accounts for most of the epidemic growth. However, there is a significant heterogeneity between studies with a secondary attack rate ranging from $4 \%$ to $55 \%$ (27). The objective of this study is to analyse some variables between the index cases and the secondary cases of COVID-19 in the family unit, to seek information on the prevalence of secondary cases and the characteristics associated with them, in the context of general medicine in Toledo (Spain).

\section{Material and methods}

An observational and retrospective study of families in which there was at least one polymerase chain reaction
(PCR) confirmed COVID-19 case, was conducted March 15 to December 31, 2020, in a general medicine office in Toledo, Spain. The outcome of interest was secondary transmission of SARS-CoV-2 within the family, and the variables collected were analysed as predictors of secondary transmission.

\section{The diagnosis of COVID-19}

The diagnosis was confirmed with PCR oropharyngeal. The cases included confirmed cases and asymptomatic carriers. Information on COVID-19 patients and their contacts was obtained from the registry systems used by general medical services in the consultation.

\section{Secondary attack rate}

Secondary attack rate was defined as the number of new cases divided by the number of people exposed to a primary case. The existence of second or third generation cases was not assessed. The cases for the determination of the attack rate included confirmed symptomatic cases and asymptomatic cases.

\section{Household contacts}

Household contacts were defined as people who shared a residence with the COVID-19 index case. We defined family members as those who had lived with primary cases in a house 4 days before and for more than 24 hours after the primary cases developed illness related to COVID-19. Families with secondary transmission were defined as those where some or all the family members become infected within one incubation period ( 2 weeks) of symptom onset of the primary case.

The onset date of a confirmed case was defined as the date of the first appearance of self-reported clinical symptoms (28). The onset date for an asymptomatic carrier was defined as the date a positive COVID-19 PCR test was obtained (28). Contacts were quarantined shortly after the index case was diagnosed, thereby reducing the risk of transmission (a provision not available in all circumstances).

\section{Collected variables}

Data on the index case and close contacts were extracted from the medical records of the general medicine practice under study. The following variables were collected: age, sex, symptoms, chronic diseases (defined as "any alteration or deviation from normal that has one or more of the following characteristics: is permanent, leaves residual impairment, is caused by a non-reversible pathological 
alteration, requires special training of the patient for rehabilitation, and / or can be expected to require a long period of control, observation or treatment" (29), classified according to the International Statistical Classification of Diseases and Health-Related Problems, CD-10 Version: 2019 (30), socialoccupancy class (according to the Registrar General's classification of occupations and social status code) $(31,32)$, problems in the family context and low income household based on the genogram and in the experience of the general practitioner (GP) for their continuity of care and knowledge of the family (genogram is a schematic model of the structure and processes of a family, which included the family structure, life cycle and family relational patterns. It was understood that "complex" genograms present families with psychosocial problems) (33-36), and severity of the disease (mild cases: clinical symptoms are mild and no manifestation of pneumonia can be found on images; moderate cases: with symptoms such as fever and respiratory tract symptoms, and the manifestation of pneumonia can be seen on the imaging tests; and severe cases: respiratory distress, respiratory rate $\geq 30$ breaths / $\mathrm{min}$; pulse oxygen saturation $\leq 93 \%$ with room air at rest; arterial partial pressure of oxygen / oxygen concentration $\leq 300$ $\mathrm{mmHg}$ ) (28). To simplify comparison, moderate and

\section{Results}

39 families with 132 cohabitants with a primary case of COVID-19 were included, and whose members were treated in the same consultation and all medical information was available. Family size was $3.38 \pm$ 0.96 members (arithmetic mean \pm standard deviation). There were 92 family members, of which 22 had negative PCR $(22 / 92=24 \%)$, one new-born who did not have PCR and was asymptomatic, and 70 secondary cases with positive PCR. Assuming all these secondary cases were infected by their index cases, this assumes a Secondary attack rate of $76 \%$. Of these 70 secondary cases, 25 were asymptomatic $(25 / 70=36 \%)$, (Figure 1).

Family secondary cases compared to primary ones were statistically significantly more women $(73 \%$ vs. $51 \% ; \mathrm{X}^{2}=5.134 . \mathrm{P}=0.023462$ ), younger (average 32 years vs. 39 years; $\mathrm{t}=1.68266$. $\mathrm{P}=0.047679)$, more students and a lower socio-occupational level $\left(\mathrm{X}^{2}=\right.$ 9.1906. $\mathrm{P}=0.026861)$, more asymptomatic $(36 \% \mathrm{v}$, $8 \% ; \mathrm{X} 2=10.3025 . \mathrm{P}=0.001328)$, with shorter duration of the symptoms (mean 5 vs. 12 days: $\mathrm{t}=$ 3.34631. $\mathrm{P}=0.000565)$, and less severe (96\% mild vs. $85 \% ; X^{2}=4.0729 . p=0.043576$ ). Tables 1,2 and 3 show the comparison of the variables studied between the primary $(\mathrm{n}=39)$ and secondary $(\mathrm{n}=70)$ cases. No severe cases were counted together.

Sample

A convenience sampling was used. The families participating in the study were chosen because they had their members in the same consultation and all medical information was available.

\section{Sample size}

Sample size was calculated for an unpaired study for a two-sided confidence level (1-alpha) of 95, a Power (\% probability of detection) of 80 , a Ratio of $1: 2$, a hypothetical ratio of asymptomatic primary cases of $10 \%$, and hypothetical proportion of asymptomatic secondary cases of $35 \%$ exposure. Thus, total Sample Size (Kelsey) should be 86; 29 primary cases and 57 secondary cases (37).

\section{Statistical analysis}

The bivariate comparisons were performed using the Chi Square test $\left(\mathrm{X}^{2}\right), \mathrm{X}^{2}$ with Yates correction or Fisher Exact Test when necessary, (according to the number the expected cell totals) for percentages, and the Student $t$ test for the mean.

differences were found by ethnic minority, or level of household income, or being a complex family, showing a high frequency of these variables (almost a quarter of the cases) in both primary and secondary cases. Genograms of various families are presented as examples in Figures 2-8 (partial genograms showing only cohabiting members; where yellow square symbol indicates the index case, broken line represents conflict, and parallel lines represent close bond). There were also no differences due to the type of symptom, or the presence of chronic diseases according to WHO groups. 


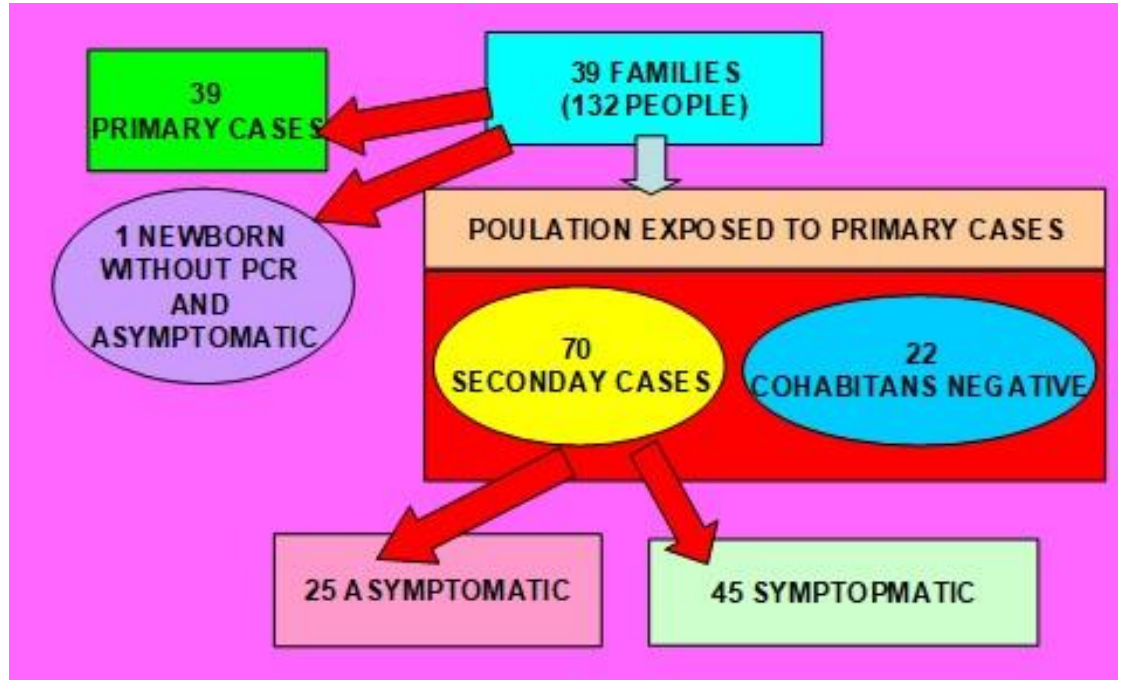

Figure 1. Study flowchart and main results

Table 1. Comparison between primary cases $(\mathrm{N}=39)$ and secondary cases in the family $(\mathrm{N}=70)$

\begin{tabular}{|c|c|c|c|}
\hline Variables & $\begin{array}{l}\text { Primary cases } \\
(\%)\end{array}$ & $\begin{array}{l}\text { Secondary cases } \\
(\%)\end{array}$ & Statistical significance \\
\hline Woman & $20(51)$ & $51(73)$ & $\begin{array}{l}\mathrm{X}^{2}=5.134 . \mathrm{P}=0.023462 \\
\text { Significant at } \mathrm{P}<0.05\end{array}$ \\
\hline $\begin{array}{l}\text { Age (years) (arithmetic mean and } \\
\text { standard deviation) and range }\end{array}$ & $\begin{array}{l}38.89+-15.41 \\
\text { Range: } 12-67\end{array}$ & $\begin{array}{l}\text { 32.45+- } 20.93 \\
\text { Range: } 1-89\end{array}$ & $\begin{array}{l}\mathrm{t}=1.68266 . \mathrm{P}=0.047679 \\
\text { Significant at } \mathrm{P}<0.05\end{array}$ \\
\hline$>=65$ years & 0 & $6(9)$ & Fisher's exact test $=0.0863 . \mathrm{NS}$ \\
\hline \multicolumn{4}{|l|}{ Social-occupancy class } \\
\hline $\begin{array}{l}\text { Intermediate occupations and Specialized } \\
\text { white-collar-workers }\end{array}$ & $5(13)$ & $8(11)$ & \multirow[t]{4}{*}{$\begin{array}{l}\mathrm{X}^{2}=9.1906 . \mathrm{P}=0.026861 \\
\text { Significant at } \mathrm{P}<0.05\end{array}$} \\
\hline $\begin{array}{l}\text { Specialized and semiskilled workers } \\
\text { manuals }\end{array}$ & $16(41)$ & $12(17)$ & \\
\hline Unskilled workers & $11(28)$ & $23(33)$ & \\
\hline Students & $7(18)$ & $27(39)$ & \\
\hline Ethnic minority & $8(20)$ & $23(33)$ & $\mathrm{X}^{2}=1.8753 . \mathrm{P}=0.170871 . \mathrm{NS}$ \\
\hline Low-income household & $7(19)$ & $23(33)$ & $\mathrm{X}^{2}=0.1883 . \mathrm{NS}$ \\
\hline Complex family & $8(20)$ & $12(17)$ & $X^{2}=0.1899$. NS. \\
\hline Asymptomatic & $3(8) *$ & $25(36)$ & $\begin{array}{l}\mathrm{X}^{2}=10.3025 . \mathrm{P}=0.001328 \\
\text { Significant at } \mathrm{P}<0.05\end{array}$ \\
\hline
\end{tabular}

* These were people who underwent PCR for being contacts of cases outside the family. NS: Not significant at $\mathrm{P}<0.05$. 
Table 2. Comparison of symptoms between primary $(\mathrm{N}=39)$ and secondary cases in the family $(\mathrm{N}=70)$

\begin{tabular}{|c|c|c|c|}
\hline Symptoms* & $\begin{array}{l}\text { Primary cases } \\
(\%)\end{array}$ & $\begin{array}{l}\text { Secondary cases } \\
(\%)\end{array}$ & Statistical significance \\
\hline General (discomfort, Asthenia, Myalgia, fever) & $46(38)$ & $38(31)$ & $\mathrm{X}^{2}=1.066 . \mathrm{NS}$ \\
\hline $\begin{array}{l}\text { Respiratorios (Cough, Dyspnea, Chest pain, } \\
\text { Neumonia) }\end{array}$ & $38(31)$ & $40(33)$ & $\mathrm{X}^{2}=0.1017 . \mathrm{NS}$ \\
\hline $\begin{array}{l}\text { ORL (Anosmia / Ageusia, Odynophagia, } \\
\text { Rhinorrhea) }\end{array}$ & $18(15)$ & $17(14)$ & $\mathrm{X}^{2}=0.0245 . \mathrm{NS}$ \\
\hline $\begin{array}{l}\text { Digestivos (Anorexia, Nausea / Vomiting, } \\
\text { Diarrhea, Dolor abdominal) }\end{array}$ & $7(6)$ & $11(9)$ & $\mathrm{X}^{2}=0.9959 . \mathrm{NS}$ \\
\hline Neurologicos (Headache, mareo & $11(9)$ & $9(7)$ & $\mathrm{X}^{2}=0.2004 . \mathrm{NS}$ \\
\hline Psiquiátricos (Anxiety, Insomnia) & $2(1)$ & $3(3)$ & $\begin{array}{l}\mathrm{X}^{2} \text { with Yates correction }= \\
0.0001 . \text { NS. }\end{array}$ \\
\hline Piel (Chilblains, Flictenas, exantema) & 0 & $3(3)$ & $\begin{array}{l}\text { Fisher's exact test }=0.1219 \text {. } \\
\text { NS. }\end{array}$ \\
\hline Total symptoms & $122(100)$ & $121(100)$ & \\
\hline $\begin{array}{l}\text { Duration of symptoms in days (arithmetic } \\
\text { mean and standard deviation) and range } \\
\text { Gravedad }\end{array}$ & $\begin{array}{l}\text { 12.12+- } 12.56 \\
\text { Range: } 0 * *-60\end{array}$ & $\begin{array}{l}5.52+-8.00 \\
\text { Range: } 0^{* *-34}\end{array}$ & $\begin{array}{l}\mathrm{t}=3.34631 . \mathrm{P}=0.000565 \\
\text { Significant at } \mathrm{P}<0.05\end{array}$ \\
\hline Mild cases & $33(85)$ & $67(96)$ & $\begin{array}{l}\mathrm{X}^{2}=4.0729 . \mathrm{P}=0.043576 \\
\text { Significant at } \mathrm{P}<0.05\end{array}$ \\
\hline Moderate-severe cases & $6(15)$ & $3(4)$ & $\begin{array}{l}\mathrm{X}^{2}=4.0729 . \mathrm{P}=.043576 \\
\text { Significant at } \mathrm{P}<0.05\end{array}$ \\
\hline Exitus & $1(3)$ & $1(1)$ & Fisher's exact test $=1 . \mathrm{NS}$. \\
\hline
\end{tabular}

* Patients could have more than one symptom. The percentages are over the total of symptoms of primary cases and of secondary cases.

** Asymptomatic cases were computed as zero days of symptom duration.

NS: Not significant at $\mathrm{P}<0.05$.

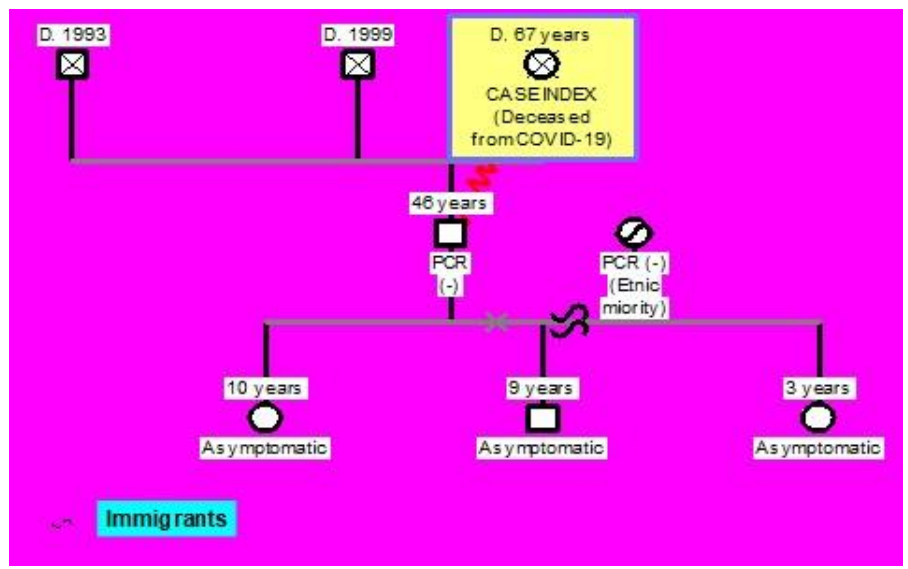

Figure 2. The characteristics of family 1 
Table 3. Comparison of chronic diseases between primary $(\mathrm{N}=39)$ and secondary cases in the family $(\mathrm{N}=70)$

\begin{tabular}{|l|l|l|l|}
$\begin{array}{l}\text { Chronic diseases according to } \\
\text { who, ICD-10 groups * }\end{array}$ & Primary cases (\%) & Secondary cases (\%) & Statistical significance \\
II Neoplasms & $3(10)$ & $1(1)$ & Fisher's exact test $=0.0864$. NS, \\
IV Endocrine & $7(23)$ & $21(31)$ & $X^{2}=0.6475$. NS. \\
\hline V Mental & $5(17)$ & $10(15)$ & $X^{2}=0.0481$. NS. \\
\hline VI-VIII Nervous and Senses & $2(7)$ & $6(9)$ & $\begin{array}{l}X^{2} \text { with Yates correction }= \\
0.0004 . \text { NS. }\end{array}$ \\
\hline IX Circulatory system & $4(13)$ & $5(8)$ & $\begin{array}{l}X^{2} \text { with Yates correction }= \\
0.2943 . \text { NS. }\end{array}$ \\
\hline X Respiratory system & $3(10)$ & $3(5)$ & Fisher's exact test $=0.3694$. NS. \\
\hline XI Digestive system & $1(3)$ & $5(7)$ & Fisher's exact test $=0.6626$. NS. \\
\hline XII Diseases of the skin & $1(3)$ & $3(5)$ & Fisher's exact test $=1$. NS. \\
\hline XIII Musculo-skeletal & $2(7)$ & $8(12)$ & Fisher's exact test $=0.7193$. NS. \\
XIV Genitourinary & $2(7)$ & $5(7)$ & Fisher's exact test $=1$. NS. \\
Total & $30(100)$ & $67(100)$ & - \\
\hline
\end{tabular}

*Patients could have more than one chronic disease. The percentages are over the total of chronic disease of primary and secondary cases.

NS: Not significant at $p<0.05$.

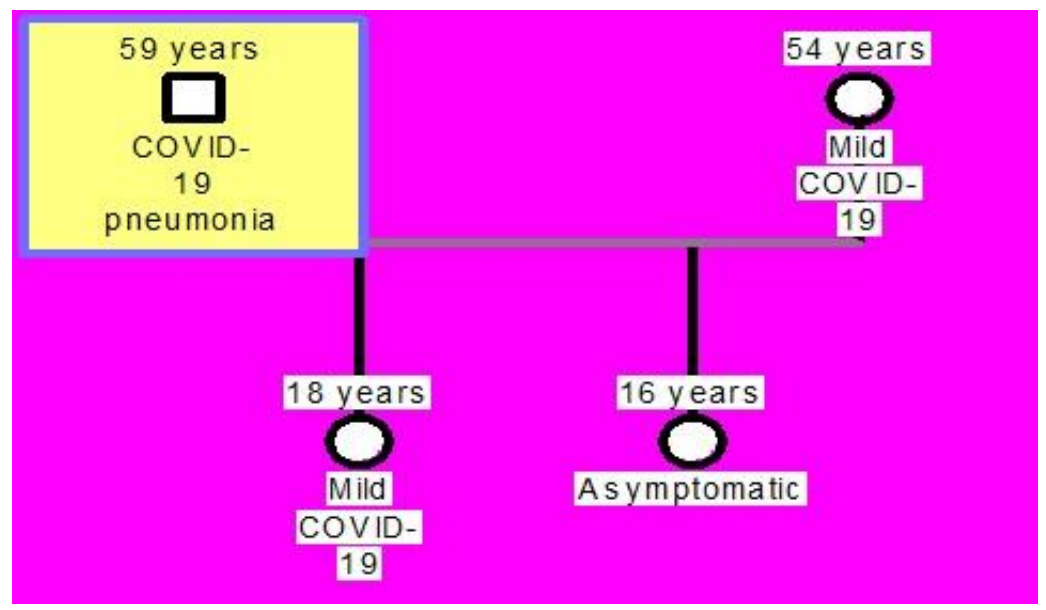

Figure 3. The characteristics of family 2 


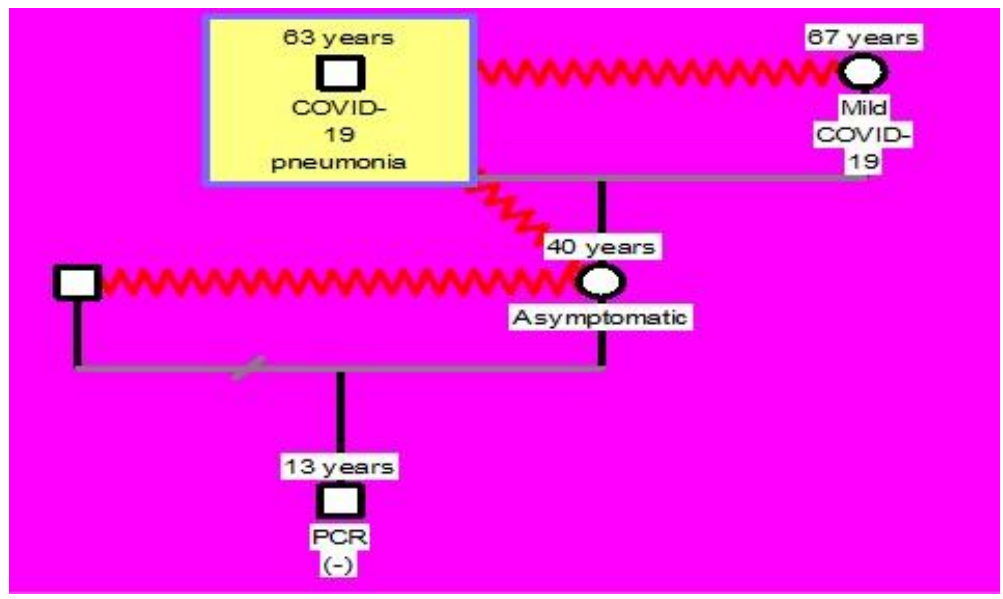

Figure 4. The characteristics of family 3

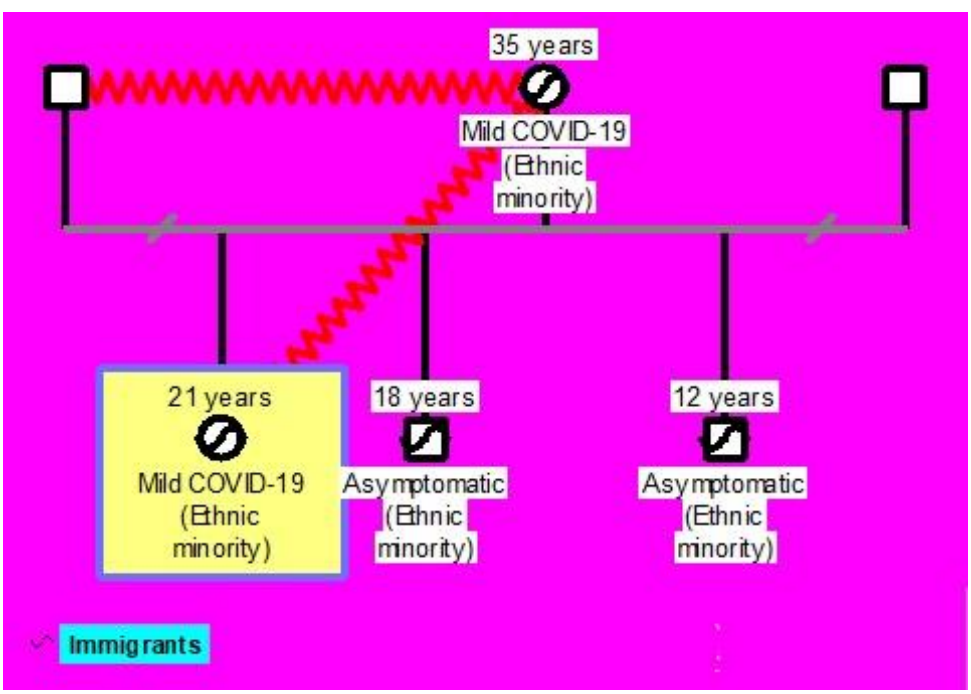

Figure 5. The characteristics of family 4

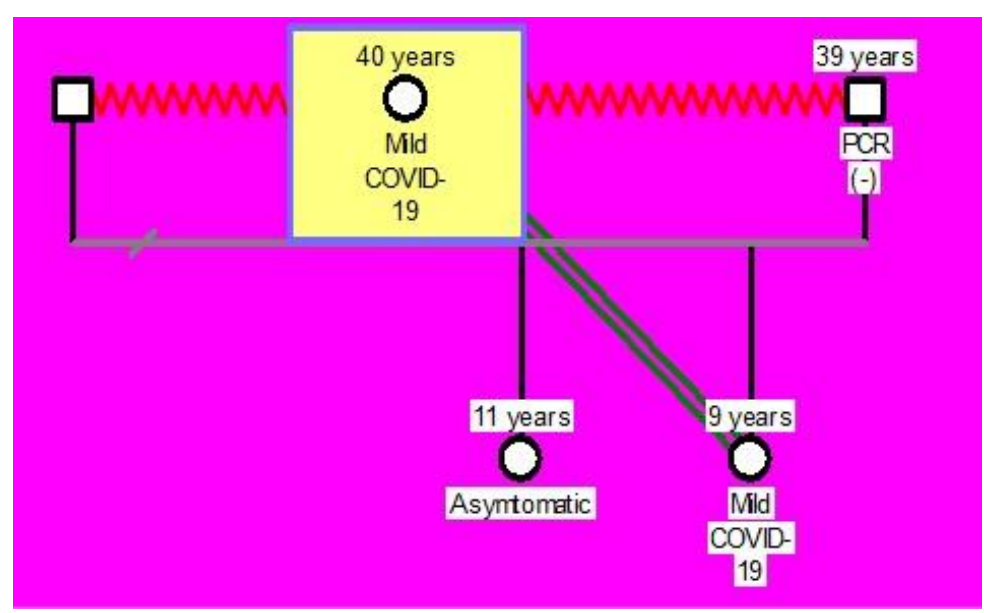

Figure 6. The characteristics of family 5 


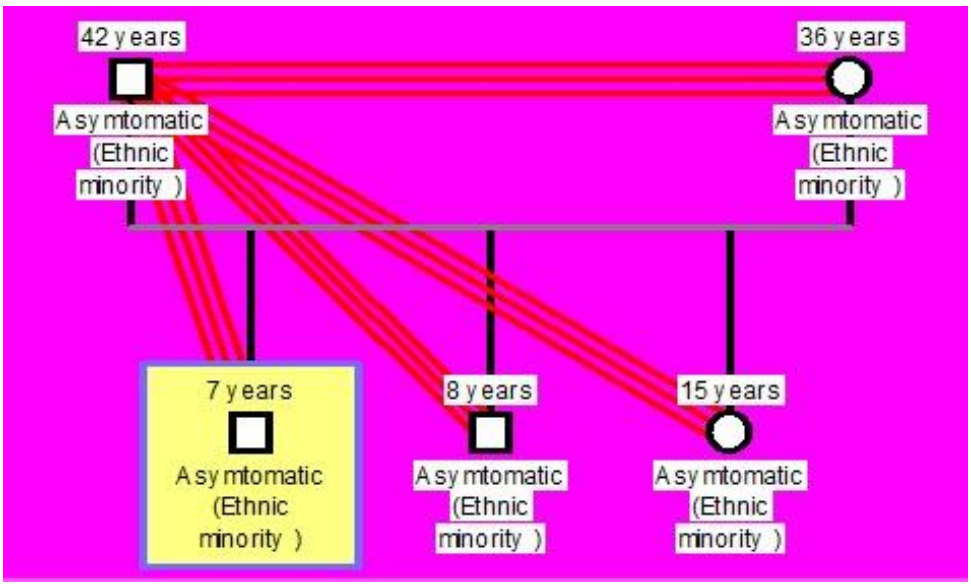

Figure 7. The characteristics of family 6

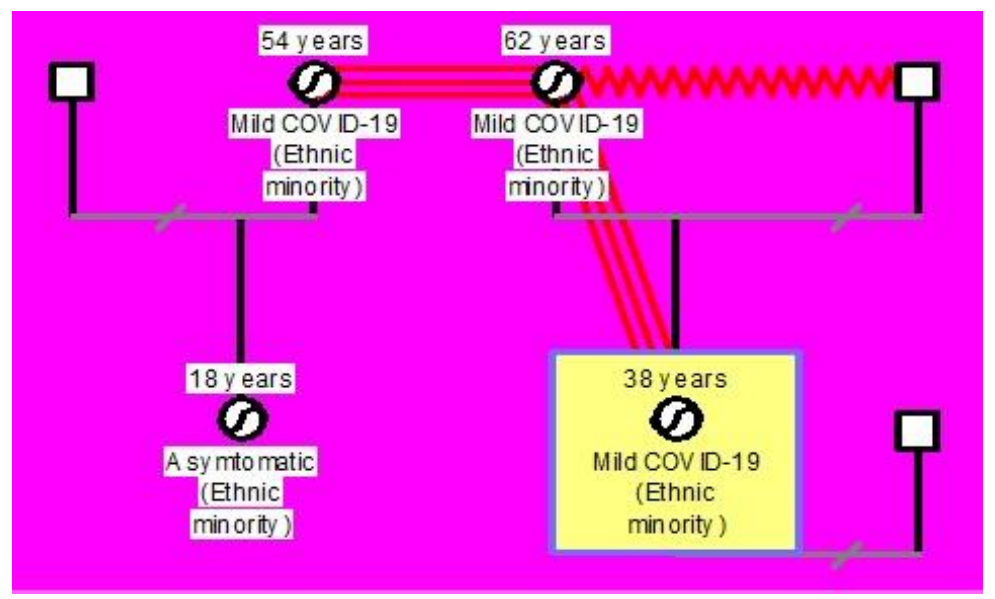

Figure 8. The characteristics of family 7

\section{Discussion}

Most people with COVID-19 receive care at home, which increases the likelihood of exposure for household members. However, less attention has been paid to family members and others who care for people with COVID-19 in the community (38). The long incubation and high presymptomatic infectivity of COVID-19 make transmission between family members a particular risk. Modelling of viral shedding suggests that the highest viral load is found at or just before the onset of symptoms, and that $44 \%$ of transmission occurs before symptoms $(38,39)$.

Preliminary evidence points to SARS-CoV2 superspreading events that predominantly occur in closed environments with poor ventilation where people are very compact and exposed for prolonged periods, particularly with face-to-face contact $(>10$ minutes) (40). Series of secondary infections resulting from short-term social events (a meal or a short visit) have been described in China and other countries, with secondary rates of $35 \%(41,42)$. So, there is evidence of how interior spaces facilitate transmission. Recent publications describe a cluster of COVID-19 outbreaks associated with a bus excursion, with an overall attack rate was $48 \%$ (43), or in a training workshop with an attack rate of 50\% (43). In addition, it has also been reported that 1 minute of speaking aloud could create at least 1,000 respiratory droplets that remain suspended in the air for up to 8 minutes. And it is estimated that these droplets can contain between 1,000-100,000 infectious viral particles (44). Analysis of contact tracing data in Hong Kong revealed that most transmission pairs infected by an identified contact (92 out of 169) involved household contacts (45). 


\section{Secondary attack rate in families}

The secondary attack rate is the proportion of people exposed to an index (or primary) case who develop the disease because of the exposure. The risk of secondary transmission has been reported to be less than $4 \%$ overall among close contacts of people diagnosed with COVID-19 and varies depending on the setting and severity of the disease (46). Exposure in the home to SARS-CoV-2 confers the greatest risk of transmission, while exposure in public transportation appears to confer the least (46). Outside of specific superspreading events, the secondary attack rate has been reported to be relatively low $(<20 \%$ for household contacts in most studies) (40).

If anything, transmission at home, unsurprisingly, is common. However, there is significant heterogeneity between studies with a rate ranging from $3.9 \%$ to $54.9 \%$ (27). A PubMed search using the keywords "COVID-19" OR "SARS-CoV-2" and "secondary attack rate" returned 17 articles in English that estimated the secondary attack rate in various groups. Of these studies, 11 (from mainland China, Hong Kong, Taiwan, and South Korea) examined secondary attack rates among community cohorts, while the others were limited to specific close-contact settings. The various community cohort studies analysed 27 to 585 index cases and 106 to 4007 close contacts and reported home attack rates ranging from $7.6 \%$ to $23 \%$ (47).

A meta-analysis to examine the evidence for home transmission of SARS-CoV-2, using PubMed search through October 19, 2020, which identified a total of 54 relevant studies with 77,758 participants reporting secondary transmission at home, found an estimated rate of secondary attack in the home of $17 \%$ (48). A study that looked at transmission in approximately 100 households in which someone had COVID-19 in Tennessee and Wisconsin found a 53\% secondary infection rate among household contacts of people with COVID-19 (49). In a study of 125 families in Beijing in which at least one member contracted COVID-19, nearly a quarter of the household members were subsequently infected. The secondary attack rate in families was $23.0 \%$ (77/335), and 41 primary cases caused 77 secondary cases, with a median number of secondary cases in families of 2 (50). Other researchers have reported a secondary attack rate at home, as detected by repeat PCR tests, of approximately $11 \%$ (51). In another study in western Norway by detecting antibodies against SARS-CoV2 , at 6 weeks after the index patient tested positive by PCR, rates were found substantially higher attack rates. Of 158 cases, $125(79 \%)$ were positive for antibodies and $12(8 \%)$ were defined as borderline. In
77 household members, $24(31 \%)$ tested positive and two $(3 \%)$ were borderline (52). In another study where family groups represented $69 \%$ of the clusters analysed, the average secondary attack rate was $6.11 \%$ (28).

For other authors, household contacts were at higher risk, with an infection rate of $10.3 \%$ (46). In the clusters of cases in families in Guandong and Sichuan province, the intra-family secondary rate was estimated between 3 and 10\% (53). Similarly, in the cases detected in the US, this rate has been found to be $0.45 \%$ (95\% CI: $0.12 \%-1.6 \%$ ) between close contacts and $10.5 \%$ (95\% CI: $2.9 \%-31.4 \%$ ) for cohabitants of the same family (54).

The secondary attack rate of COVID-19 in the families of our study is higher than that reported by other authors in other contexts. In addition to the possible sample bias because our sample of families is not probabilistic, but rather opportunistic, we must think about other factors in our context. Public health councils recommend isolating COVID-19 positive household members, both symptomatic and asymptomatic, but this can be difficult, especially in small apartments with shared facilities. In our study, the frequency of ethnic minority people, low-income households, and family problems were high for both primary and secondary cases. Figures 2-8 may suggest the difficulties in complying with the isolation measures for family members. Furthermore, although our study does not collect it, the motivation to overcome these difficulties may not be high enough if family members are sceptical about the reduction of transmission at home and are unaware that the disease in other family members it can be more serious if it level of exposure is not reduced. The fact that secondary contacts are young and frequently asymptomatic may suggest this difficulty in compliance. Furthermore, our secondary cases were frequently women of a low socio-occupational level, who in our context tend to be willing to take care of the house and children, which also implies food shopping tasks.

\section{Clinical presentation of secondary cases}

The clinical presentation of secondary contacts with mild symptoms in $16 \%$, moderate in $68 \%$, and severe / critical in $9 \%$ has been reported (46). The rate is higher for symptomatic index cases compared to asymptomatic cases, and adults have a higher susceptibility to infection compared to children. The spouses of the index case are more likely to be infected compared to other members of the household (27). In Guangzhou, China, secondary infection rates also increased with the most severe disease in index cases and were very low with asymptomatic index cases. 
The secondary attack rate increases with the severity of the index case $(0.3 \%$ for asymptomatic cases to $6.2 \%$ for severe / critical cases) according to a study of 3,410 close contacts of 391 index cases $(46,55)$. It has also been reported that secondary attack rates in the home were higher when index cases were symptomatic $(18.0 \%)$ vs. asymptomatic $(0.7 \%)$; in adult contacts $(28.3 \%)$ vs. contacts with children $(16.8 \%)$; spouses $(37.8 \%)$ vs. other family contacts (17.8\%); and in households with 1 contact $(41.5 \%)$ vs. households with 3 or more contacts $(22.8 \%)(48)$. In a study of 125 families in Beijing, out of 64 secondary cases in adults, 83\% (53/64) were mild, 11\% (7/64) were severe, $2 \%(1 / 64)$ were critical and $5 \%(3 / 64)$ were asymptomatic (50). We found a high frequency of predominantly mild secondary cases (96\%). On average, the virus appears to be of lower risk for younger people, and women tend to do better than men (56).

\section{Asymptomatic secondary cases}

The clinical presentation of secondary contacts has been reported to be asymptomatic in 6\% (46). According to other authors, more than a third of the SARS-CoV-2 positive close contacts were asymptomatic (47). We found a high frequency of asymptomatic secondary cases $(36 \%)$.

\section{Family size, complex family, ethnic minority families, and infection}

It has been reported that no connection was found between the risk of infection and the number of all people living in the same household. But, the secondary risk of infection for study participants living in the same household increased from $15 \%$ (one person households) to $44 \%$ ( 2 people), $35 \%$ ( 3 people) and $18 \%$ (4 People), where researchers expected higher values (57). We found a family size of $3.38+-$ 0.96 members (arithmetic mean + -standard deviation).

\section{Primary vs. secondary cases in children}

Children are highly adapted to respond to new viruses. Even when infected with SARS-CoV-2, children are more likely to experience mild or asymptomatic illness (13). Children younger than 5 years had lower secondary attack rates compared to older children, and the risk of infection was higher if the index case in the household was the mother (27). In the secondary transmission group, the secondary attack rate in children under 18 years of age was $36 \%$, compared with $70 \%$ in adults, with the difference between these two age groups being significant (50). In a secondary analysis of a household contact study, researchers from Milwaukee and Salt Lake City followed a cohort of children and their household contacts, including the COVID-19 index case, for 14 days after exposure. $28 \%$ of paediatric contacts and $30 \%$ of adult contacts tested positive. Transmission to adults was similar in households with and without children. Among paediatric contacts, $68(63 \%)$ were children of an adult index case. Children reported symptoms less frequently than adults and experienced a shorter duration of symptoms. Mild or absent symptoms in children may allow the infection to go unrecognized, possibly increasing the risk of transmission $(58,59)$. In any case, studies on domestic transmission in children are biased; if only symptoms are looked for to detect initial cases, infected children are not detected because they are less likely to have symptoms (60).

\section{Implications for the general practitioner}

Effective isolation of index cases from household members is key and could reduce secondary infections (61). In view of the substantial prevalence of asymptomatic secondary infections, routine testing of close contacts regardless of symptoms should take priority. Detection of close household contacts positive for SARS-CoV-2 would lead to relocation of the person outside the home or the implementation of physical distancing and other infection prevention measures within the home. GP should encourage caregivers of positive household members to take steps to reduce infectious viral load, in order to reduce the incidence and severity of infection, using behavior change techniques to reduce virus transmission: he GP have to explain the importance and benefits of reducing exposure to motivate users to restrict their exposure; planning how to isolate an infected household member as much as possible (for example, avoiding sharing areas of the household); setting custom goals to increase infection control behaviors; changing the home environment to support new habits (for example, improving ventilation and increasing protective behaviors, such as cleaning shared surfaces); and problem solving to overcome barriers. Until an effective vaccine is widely available, strategies to prevent home transmission and to support people in quarantine will be vital and should be a fundamental part of any GP's strategy (62). Furthermore, the high rate of secondary attack in families indicates that new measures are urgently needed to protect domestic contacts. One of them may be the use of rapid antigen tests $(63,64)$. Waiting for a PCR has been an everyday occurrence for months. The advantage of antigen testing is clear: you will leave the doctor's office with the certainty of having COVID-19. Furthermore, recent surveys in the UK 
indicate that many people with COVID-19 symptoms do not self-isolate on their own initiative $(65,66)$. In this scenario, how to manage "silent" (asymptomatic) cases? identifying the points where asymptomatic cases are occurring by approaching the situation from a comprehensive perspective. This inevitably includes opportunistic tests for the detection of general and specific populations: rapid response tests for COVID19 available to everyone, specifically for those without symptoms, performed as mass population screening, to certain groups such as health workers and students; But also as opportunistic detection in the GP's office, and even in concerts, in the cinema, in large commercial surfaces, or at home self-administered by anyone (maintaining the rest of public health measures: masks, distancing, capacity limitation, hand washing, mobility limitation ). In this approach, even with the possible errors, most of the possible vectors of the disease would be detected $(67,68)$.

\section{Limitations of the study}

1. Blood samples were not obtained from the cases and their family contacts to perform genetic analysis of the infected and identify the viral strain that circulated among them, thus the transmission and causal extension of the infection from index cases to other family members, in a situation of community transmission, it was only presumptive based on the timing of onset of symptoms and / or dates of performance of the PCR $(69,70)$

2. On the other hand, children may develop symptoms of COVID-19 and specific antibodies against SARSCoV-2, but never test positive for the virus in a standard RT-PCR test (71).

3. The sample of families included was not a probabilistic sample; it was a convenience sample (families participating in the study were chosen because their members were cared for in the same consultation and all medical information was available). However, there are no logical reasons to think that the current research sample was very different from the ideal, randomly selected sample (from the entire population), nor that there might be under- or over-represented people in the sample.

4. It is only possible to determine the direction of interfamilial transmission when all cases are symptomatic (and dates of onset of symptoms are available). But when there are asymptomatic cases, it is not possible to determine, with exceptions with very evident temporality data, whether the index case was a symptomatic case with catalogued symptom onset dates or an asymptomatic case; so that both directions of transmission would be possible under those circumstances. We find many asymptomatic cases in families, preferably in children and adolescents; Thus, it is not possible to determine whether these asymptomatic children were secondary cases or index cases in the families. Although this difference does not change the mathematical calculation of the secondary attack rate, it is an important limitation, since it raises two hypotheses that cannot be clarified, they have very different implications: 1) children are asymptomatic secondary cases; or 2) children are primary cases in families. It should not be excluded at all that children and adolescents may represent a gateway for SARS Cov-2 in families.

5. Behaviors (such as the use of masks at home after the onset of the disease, compliance with isolation, eating separately, etc.), or knowledge of their own infectivity, which are associated with transmission were not analysed.

6. Finally, the third-generation cases were not identified, so they were all considered as secondary cases, but probably in this way some third-generation cases were included from close contacts of previous generation cases.

\section{Conclusion}

Most people with COVID-19 receive care at home, increasing the likelihood of exposure for household members. In the context of general medicine in Toledo (Spain), the prevalence of secondary domestic contacts is very high, with 3 out of 4 family members infected, and they occur frequently in young women, being asymptomatic or mild cases. Probably, at present, in our context, the transmission of COVID-19 within families accounts for most of the epidemic growth. Effective isolation of index cases from household members could reduce secondary infections. The high rate of secondary attack suggests the influence of the transmission of asymptomatic and non-compliance with isolation. The GP should aim to quickly detect positive cases, and improve the adherence of family contacts to isolation, improving communication and increasing the knowledge of family members about the actions to be taken.

\section{References}

1. Zhu, N., Zhang, D., Wang, W., Li, X., Yang, B., Song, J. et al. China Novel Coronavirus Investigating and Research Team. A Novel Coronavirus from Patients with Pneumonia in China, 2019. N Engl J Med 2020; 382(8):727-733.

2. Coronavirus COVID-19 Global Cases by the Center for Systems Science and Engineering (CSSE) at Johns Hopkins. The Center for Systems Science and Engineering (CSSE) at JHU. Available from: https://www.arcgis.com/apps/opsdashboard/index. 
html\#/bda7594740fd40299423467b48e9ecf6

3. Wei, W.E., Li, Z., Chiew, C.J., Yong, S.E., Toh, M.P., Lee, V.J. Presymptomatic Transmission of SARS-CoV-2 - Singapore, January 23-March 16, 2020. MMWR Morb Mortal Wkly Rep 2020; 69(14):411-415.

4. Tong, Z.D., Tang, A., Li, K.F., Li, P., Wang, H.L., Yi, J.P. et al. Potential Presymptomatic Transmission of SARS-CoV-2, Zhejiang Province, China, 2020. Emerg Infect Dis 2020; 26(5):10521054.

5. Epidemiology Working Group for NCIP Epidemic Response, Chinese Center for Disease Control and Prevention. [The epidemiological characteristics of an outbreak of 2019 novel coronavirus diseases (COVID-19) in China]. Zhonghua Liu Xing Bing Xue Za Zhi 2020; 10;41(2):145-151.

6. Rothe, C., Schunk, M., Sothmann, P., Bretzel, G., Froeschi, G., Wallrauch, C. et al. Transmission of 2019-nCoV Infection from an Asymptomatic Contact in Germany. N Engl J Med. 2020; 382(10):970-971.

7. Bai, Y., Yao, L., Wei, T., Tian, F., Jin, D.Y., Chen, L. et al. Presumed Asymptomatic Carrier Transmission of COVID-19. JAMA 2020; 323(14):1406-1407.

8. Oran, D.P., Topol, E.J. Prevalence of Asymptomatic SARS-CoV-2 Infection: A Narrative Review. Ann Intern Med 2020; 173(5): 362-367.

9. Buitrago-Garcia, D., Egli-Gany, D., Counotte, M.J., Hossmann,S., Imeri, H., Impekci, A.M. et al. Occurrence and transmission potential of asymptomatic and presymptomatic SARS-CoV-2 infections: A living systematic review and metaanalysis. Plos Medicine 2020; 17(9): e1003346.

10. Pollán, M., Pérez-Gómez, B., Pastor-Barriuso, R., Oteo, J., Herman, M.A., Pérez-Olmeda, M. et al. Prevalence of SARS-CoV-2 in Spain (ENECOVID): a nationwide, population-based seroepidemiological study. Lancet 2020; 396(10250):535-544.

11. Byambasuren, O., Cardona, M., Bell, K., Clark, J., McLaws, M.L., Glaszou, P. Estimating the extent of asymptomatic COVID-19 and its potential for community transmission: systematic review and meta-analysis. MedRxiv 2020; 2020.05.10.20097543.

12. Yu, P., Zhu, J., Zhang, Z., Han, Y. A Familial Cluster of Infection Associated With the 2019 Novel Coronavirus Indicating Possible Person-toPerson Transmission During the Incubation Period, J Infect Dis 2020; 221(11): 1757-1761.

13.Nogrady, B. What the data say about asymptomatic COVID infections. People without symptoms can pass on the virus but estimating their contribution to outbreaks is challenging. Nature News 2020; Published 18 November 2020.Updated 23 November $2020 . \quad$ Available from: https://doi.org/10.1038/d41586-020-03141-3

14. Lee, S., Kim, T., Lee, E., Lee, C., Kim, H., Rhee, $\mathrm{H}$. et al. Clinical course and molecular viral shedding among asymptomatic and symptomatic patients with SARS-CoV-2 infection in a community treatment center in the Republic of Korea. JAMA Intern Med 2020; 180(11):14471452 .

15. Lu, J., Gu, J., Li, K., Xu, C., Su, W., Lai, Z. et al. COVID-19 Outbreak Associated with Air Conditioning in Restaurant, Guangzhou, China, 2020. Emerg Infect Dis 2020; 26(7):1628-31.

16. Schwartz, N.G., Moorman, A.C., Makaretz, A., Chang, K.T., Chu, V.T., Szablewski, C.M. et al. Adolescent with COVID-19 as the Source of an Outbreak at a 3-Week Family Gathering - Four States, June-July 2020. MMWR Morb Mortal Wkly Rep 2020; 69(40):1457-1459.

17. Chan, J.F., Yuan, S., Kok, K.H., To, K.K.W., Chu, H., Yang, J. et al. A familial cluster of pneumonia associated with the 2019 novel coronavirus indicating person-to-person transmission: a study of a family cluster. Lancet 2020; 395(10223):514523.

18. Meyerowitz, E.A., Richterman, A., Gandhi, R.T., Sax, P.E. Transmission of SARS-CoV-2: A Review of Viral, Host, and Environmental Factors. Ann Intern Med 2021; 174(1):69-79.

19. Jiang, X.L., Zhang, X.L., Zhao, X.N. Li, C.B., Lei, J., Kou, Z.Q. et al. Transmission Potential of Asymptomatic and Paucisymptomatic Severe Acute Respiratory Syndrome Coronavirus 2 Infections: A 3-Family Cluster Study in China. J Infect Dis 2020; 221(12): 1948-1952.

20. Halliday, J. Oldham takes measures to avoid full coronavirus lockdown. The Guardian 2020; Published 28 July 2020. Available from: https://www.theguardian.com/uknews/2020/jul/28/oldham-greater-manchestertakes-measures-to-avoid-full-coronavirus-covid19-lockdown

21.UK Government. COVID-19: number of outbreaks in care home-management information. Published 29 April 2020. Last updated 27 August 2020. Available from: https://www.gov.uk/government/statistical-data-sets/covid-19number-of-outbreaks-in-care-homes-management-information

22. Shen, M., Peng, Z., Guo, Y., Rong, L., Li, Y., Xiao, Y. et al. Assessing the effects of metropolitan-wide quarantine on the spread of COVID-19 in public space and households. Int J Infect Dis 2020; 96:503-5. 
23. Yu, H.J., Hu, Y.F., Liu, X.X., Yao, X.Q., Wang, Q.F., Liu, L.P. et al. Household infection: The predominant risk factor for close contacts of patients with COVID-19. Travel Med Infect Dis 2020; 36:101809.

24. Nishiura, H., Oshitani, H., Kobayashi, T., Saito, T., Sunagawa, T., Matsul, T. et al. Closed environments facilitate secondary transmission of coronavirus disease 2019 (COVID-19). medRxiv 2020; 2020.02.28.20029272.

25. Rosenberg, E.S., Dufort, E.M., Blog, D.S., Hall, E.W., Hoefer, D., Backenson, B.P. et al. COVID19 Testing, Epidemic Features, Hospital Outcomes, and Household Prevalence, New York State-March 2020. Clin Infect Dis 2020; 71(8): 1953-1959.

26. Wu, J., Huang, Y., Tu, C., Bi, C., Chen, Z., Luo, L. et al. Household Transmission of SARS-CoV-2, Zhuhai, China, 2020. Clin Infect Dis 2020; 71(16): 2099-2108.

27.Beeching, N.J., Fletcher, T.E., Fowler, R. Coronavirus disease 2019 (COVID-19). BMJ Best Practice 2020. Last updated: 21 December 2020. Available from: https://bestpractice.bmj.com/topics/en$\mathrm{gb} / 3000168 / \mathrm{pdf} / 3000168 /$ Coronavirus\%20disease $\% 202019 \% 20 \% 28$ COVID-19\%29.pdf

28. Mao, S., Huang, T., Yuan, H., Li, M., Huang, X., Yang, C. et al. Epidemiological analysis of 67 local COVID-19 clusters in Sichuan Province, China. BMC Public Health 2020; 20: 1525.

29. Strauss, A.L. Chronic illness and the quality of life. St Louis: The C.V. Mosby Company. 1984

30. WHO. International Statistical Classification of Diseases and Health-Related Problems. ICD-10 Version:2019. Available from: https://icd.who.int/browse10/2019/en

31. Royal Collage of General Practitioners. The Classification and Analysis of General Practice Data. Occasional paper. No. 26. 1986.

32. Donaldson, R.J., Donaldson, L.J. Essential Community Medicine. Lancaster: MTP Press. 1983.

33. Turabian, J.L. Family Genogram in General Medicine: A Soft Technology that can be Strong. An Update. Res Med Eng Sci 2017; 3(1):186-191.

34. Russell, L.T. Capturing Family Complexity in Family Nursing Research and Practice. J Fam Nurs 2020; 26(4):287-293.

35. Watts, C., Shrader, E. How to do (or not to do)... The genogram: a new research tool to document patterns of decision-making, conflict and vulnerability within households. Health Policy Plan 1998; 13(4): 459-464.

36. McIlvain, H., Crabtree, B., Medder, J., Strange, K.,
Miller, W.L. Using practice genograms to understand and describe practice configurations. Fam Med 1998; 30(7): 490-496.

37. Open Source Epidemiologic Statistics for Public Health (Openepi). Available from: http://www.openepi.com/SampleSize/SSCC.htm

38. Little, P., Read, R.C., Amlôt, R., Chatborn, T., Rice, C., Bostock, J. et al. Reducing risks from coronavirus transmission in the home - the role of viral load. BMJ 2020; 369:m1728.

39. He, X., Lau, E.H.Y., Wu, P., Deng, X., Wang, J., Hao, X. et al. Temporal dynamics in viral shedding and transmissibility of COVID-19. Nat Med 2020; 26(5):672-675.

40. Meyerowitz, E.A., Richterman, A.G. Viral Shedding and COVID-19 Superspreading Events. Medscape 2020; Published 08 June 2020. Available from: https://www.medscape.com/viewarticle/931898.

41. Liu, Y., Eggo, R.M., Kucharski, A.J. Secondary attack rate and superspreading events for SARSCoV-2. The Lancet 2020; 395(10227): E47.

42. Centro de Coordinación de Alertas y Emergencias Sanitarias. [Scientific-technical information Coronavirus disease, COVID-19 Update; March 26th. 2020 (version 2)]. Ministerio de Sanidad. [Article in Spanish]. Available from: https://www.mscbs.gob.es/profesionales/saludPub lica/ccayes/alertasActual/nCovChina/documentos/20200326 ITCoronavirus.pdf

43. Shen, Y., Li, C., Dong, H. Wang, Z., Martinez, L., Sun, Z. et al. Airborne transmission of COVID-19: epidemiologic evidence from two outbreak investigations (Preprint). Available from: https://duurzaam.d66.nl/content/uploads/sites/102/ 2020/05/Shen-2020-Airborne-transmission-ofCOVID-19-epidemiologic-evidence-from-twooutbreak-investigations-budhists.pdf

44. Stadnytskyi, V., Bax, C.E., Bax, A., Anfinrud, P. The airborne lifetime of small speech droplets and their potential importance in SARS-CoV-2 transmission. Proceedings of the National Academy of Sciences (PNAS) 2020; 117 (22): 11875-1877.

45. Carvalho, T. COVID-19 clusters. Nat Med 2020; 26:1806.

46. Luo, L., Liu, D., Liao, X., Wu, X., Jing, Q., Zheng, $\mathrm{J}$. et al. Contact settings and risk for transmission in 3410 close contacts of patients with COVID-19 in Guangzhou, China: A prospective cohort study. Ann Intern Med 2020; 173(11):879-887.

47. Ng, O.Y., Marimuthu, K., Koh, V., Pang, J., Linn, K.Z., Sun, J. et al. SARS-CoV-2 seroprevalence and transmission risk factors among high-risk close 
contacts: a retrospective cohort study. Lancet Infect Dis 2020; 20:1-11.

48.Madewell, Z.J., Yang, Y., Longini, I.M. Jr, Halloran, M.E., Dean N.E. Household Transmission of SARS-CoV-2: A Systematic Review and Meta-analysis. JAMA Netw Open 2020; 3(12): e2031756.

49. Grijalva, C.G., Rolfes, M.A., Zhu, Y., McLean, H.Q., Hanson, K.E., Belongia, E.A. et al. Transmission of SARS-COV-2 Infections in Households - Tennessee and Wisconsin, AprilSeptember 2020. MMWR Morb Mortal Wkly Rep 2020; 69(44):1631-1634.

50. Wang, Y., Tian, H., Zhang, L., et al, Reduction of secondary transmission of SARS-CoV-2 in households by face mask use, disinfection, and social distancing: a cohort study in Beijing, China. BMJ Global Health 2020; 5: e002794.

51. Bi, Q.F., Wu, Y.S., Mei, S.J. Ye, C., Zou, X., Zhang, Z. Epidemiology and transmission of COVID-19 in 391 cases and 1286 of their close contacts in Shenzhen, China: a retrospective cohort study. Lancet Infect Dis 2020; 20:911-919.

52.Cox, R.J., Brokstad, K.A., Krammer, F., Langeland, N. for the Bergen COVID-19 Research Group. Seroconversion in household members of COVID-19 outpatients. Lancet Infect Dis 2020; 20:1.

53. Report of the WHO-China Joint Mission on Coronavirus Disease 2019 (COVID-19). 16-24 Feb. 2020. Available from: https://www.who.int/docs/defaultsource/coronaviruse/who-china-joint-mission-oncovid-19-final-report.pdf

54.Burke, R.M. Midgley, C.M., Dratch, A., Fenstersheib, M., Haupt, T., Holshue, M. et al. Active Monitoring of Persons Exposed to Patients with Confirmed COVID-19 - United States, January-February 2020. MMWR Morb Mortal Wkly Rep 2020; 69(9);245-246.

55. Lu, S., Lin, J., Zhang, Z., Xiao, L., Jiang, Z., Chen, J. et al. Alert for non-respiratory symptoms of Coronavirus Disease 2019 (COVID-19) patients in epidemic period: a case report of familial cluster with three asymptomatic COVID-19 patients. J Med Virol 2021; 93(1):518-521.

56. Cunningham, J.W., Vaduganathan, M., Claggett, B.L., Jering, K.S., Bhatt, A.S., Rosenthal, N. et al. Clinical Outcomes in Young US Adults Hospitalized With COVID-19. JAMA Intern Med 2020: E1-E7.

57. van den Heuvel, M. [High number of unreported infections, death rate only $0.36 \%$ - does this apply to the whole of Germany?]. [Article in German]. Medscape 2020 May,5; Available from: https://deutsch.medscape.com/artikelansicht/4908 $\underline{853}$

58. van der Hoek, W., Backer, J.A., Bodewes, R., Friesema, I., Meijer, A., Pijnacker, R. et al. The role of children in the transmission of SARS-CoV2. Nederlands Tijdschrift Voor Geneeskunde, NTvG 2020. Available from: https://www.ntvg.nl/artikelen/de-rol-vankinderen-de-transmissie-van-sars-cov-2/abstract

59. Laws, R.L., Chancey, R.J., Rabold, E.M., et al. Symptoms and Transmission of SARS-CoV-2 Among Children - Utah and Wisconsin, MarchMay 2020. Pediatrics 2021; 147(1): e2020027268.

60.Hanage, W.P. [COVID-19 Data Prospecting: Many Reasons Reopening Schools Can Go Wrong]. [Article in Spanish]. Medscape 2020 September,7. Available from: https://espanol.medscape.com/verarticulo/590589 6? src $=\mathrm{mkm}$ latmkt 200926 mscmrk top5latam

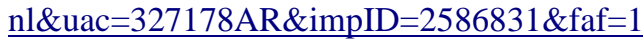

61. Dattner, I., Goldberg, Y., Katriel, G., Yaari, R., Gal, N., Miron, Y. et al. The role of children in the spread of COVID-19: using household data from Bnei Brak, Israel, to estimate the relative susceptibility and infectivity of children. MedRxiv 2020; 2020.06.03.20121145. Available from: https://www.medrxiv.org/content/10.1101/2020.0 $\underline{6.03 .20121145 \mathrm{v} 2 \text { ?ijkey }=057 \mathrm{fd} 44 \mathrm{a} 8197 \mathrm{c} 727853 \mathrm{c} 8}$ 4a39df408b97554a1c0\&keytype2=tf ipsecsha

62. Haroo, S., Chandan, J.S., Middleton, J., Cheng, K.K. Covid-19: breaking the chain of household transmission. BMJ 2020; 370:m3181.

63.The European Commission. Commission recommendation of 18.11.2020 on the use of rapid antigen tests for the diagnosis of SARS-CoV-2 infection. Brussels, 18 November 2020. C (2020) 8037 Final. Available from: https://ec.europa.eu/health/sites/health/files/prepar edness_response/docs/sarscov2_rapidantigentests recommendation_en.pdf

64. Albert, E., Torres, I., Bueno, F., Huntley, D., Molla, E., Fernandez-Fuentes, M.A. et al. Field evaluation of a rapid antigen test (Panbio $^{\text {TM }}$ COVID-19 Ag Rapid Test Device) for COVID-19 diagnosis in primary healthcare centres. Clin Microbiol Infect 2020; S1198-743X(20)30697-2.

65. Smith, L.E., Potts, H.W.W., Amlot, R., Fear, N.T., Michie, S., Rubin, J. Adherence to the test, trace and isolate system: results from a time series of 21 nationally representative surveys in the UK (the COVID-19 Rapid Survey of Adherence to Interventions and Responses [CORSAIR] study). MedRxiv 2020; 2020.09.15.20191957.

66. Smith, L.E., Amlôtb, R., Lambert, H., Oliver, I., Robin, C., Yardley, L. et al. Factors associated with 
adherence to self-isolation and lockdown measures in the UK: a cross-sectional survey. Public Health 2020; 187: 41-52.

67. Pray, I.W., Ford, L., Cole, D., Lee, C., Bigouette, J.P., Abedi, G.R. et al. Performance of an AntigenBased Test for Asymptomatic and Symptomatic SARS-CoV-2 Testing at Two University Campuses - Wisconsin, September-October 2020. MMWR Morb Mortal Wkly Rep 2021; 69(5152):1642-1647.

68. Serhani, M., Labbardi, H. Mathematical modeling of COVID-19 spreading with asymptomatic infected and interacting peoples. J Appl Math Comput 2020; 1-20.

69. Winter, L. Conference Linked to as Many as 300,000 COVID-19 Cases: Study. Around 100 people were infected at a scientific meeting hosted by Biogen in Boston in February. Then they went back home, taking the virus with them. The Scientist 2020; Dec 14. Available from: https://www.the-scientist.com/newsopinion/conference-linked-to-as-many-as-300000-covid-19-cases-study-68274

70. Lemieux, J.E., Siddle, K.J., Shaw, B.M., Loreth, C., Schaffner, S.F., Gladden-Young, A. et al. Phylogenetic analysis of SARS-CoV-2 in Boston highlights the impact of superspreading events. Science 2020; eabe3261.

71. Nogrady, B. How kids' immune systems can evade COVID. Childrens' untrained immune response seems to be key to eliminating SARS-CoV-2. Nature 2020; 588:382. 